\title{
ESTUDO DA ATIVIDADE ANTIFÚNGICA DE Ottonia martiana Miq., PIPERACEAE: UM TESTE IN VIVO
}

\author{
STUDY IN VIVO OF ANTIFUNGICAL ACTIVITY OF \\ Ottonia martiana Miq., PIPERACEAE.
}
CUNICO, M. M. ${ }^{1,4}$; MIGUEL, O. G. ${ }^{1,4 *}$; MIGUEL, M. D. 4,5; CARVALHO, J. L. S ${ }^{1,3,4}$, PEITZ, C. 1,4; AUER, C. G. ${ }^{2} ;$ GRIGOLETTI JÚNIOR, . $^{2}$

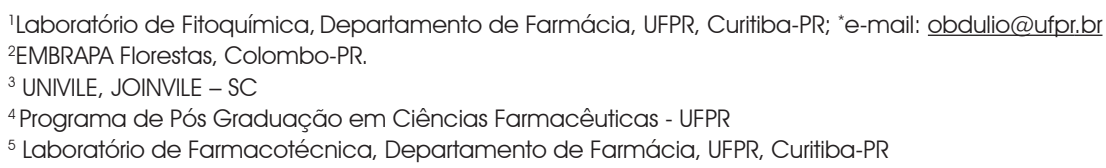

\section{RESUMO}

Atualmente, a procura por novos agentes antimicrobianos, a partir de plantas, vem sendo intensificada devido à crescente resistência de pragas, microrganismos fitopatogênicos e ervas daninhas aos produtos sintéticos. Dentre várias espécies vegetais da flora nativa brasileira com potencial fungitóxico, encontra-se a Ottonia martiana Miq., arbusto comum da Floresta Atlântica e conhecida como "anestésia" pelos nativos do litoral paranaense. Devido à sua ação anestésica sobre a mucosa oral, raízes e partes aéreas são popularmente utilizadas em odontalgias, na forma (in natura) de fragmentos ou alcoolaturas. Por apresentar em sua composição amidas que são consideradas substâncias bioativas, avaliou-se o potencial fungitóxico desta espécie frente ao patógeno Cylindrocladium spathulatum, pelo teste de inibição do crescimento micelial. Os resultados obtidos mostraram que $O$. martiana apresenta atividade antifúngica, pois o seu extrato inibiu em mais de $40 \%$ o crescimento micelial do C. spathulatum em folhas de llex paraguariensis (ervamate).

Palavras-chave: Cylindrocladium spathulatum; llex paraguariensis; anestésia.

\section{ABSTRACT}

Actually, research is looking for new antimicrobial agents from plants whide is intensified by increesed resistance of pests against chemicals. Among several species from brazilian native flora with fungitoxic potential, there is Ottonia martiana Miq., common shrub in Atlantic Tropical Forest, known as "anesthetic" by native people of Paraná beach. Due to its anesthetic action on oral mucous, roots and foliage parts are commonly used to releaf toothache, in natura, as fragments or alcoholic preparations. In its composition are amides that are considered bioactive substances. The objective of this work was to evaluate the fungitoxic potential of $O$. martiana extract against a foliar pathogen on llex paraguariensis, Cylindrocladium spathulatum. An ethanolic extract was used in a inhibition assay on mycelial growth. Results showed antifungal activity of O. martiana, inhibiting over $40 \%$ of mycelial growth of C. spathulatum on I. paraguariensis leaves.

Key words: Cylindrocladium spathulatum; llex paraguariensis; anesthetic.

\section{INTRODUÇÃO}

Atualmente, a busca por alternativas tecnológicas para a produção de alimentos, espécies vegetais e fitoterápicos com boa qualidade e reduzido impacto ambiental, considera o efeito das pragas e doenças sobre a produção. O uso indiscriminado e excessivo de agrotóxicos ao longo dos anos gerou a crescente resistência de pragas, microrganismos fitopatogênicos e ervas daninhas aos produtos sintéticos, de alto custo econômico e ambiental, tornando insustentável os sistemas de produção dos mesmos (COUTINHO, 1996).

Com isto, a pesquisa tem apontado para o potencial, ainda inexplorado, das plantas medicinais no controle de fitopatógenos, as quais, quando comparadas com fungicidas de origem sintética, representam uma proposta viável e ecologicamente inofensiva ao meio ambiente (STANGARLIN et. al., 1999).

Dentre as várias espécies vegetais da flora nativa brasileira com potencial fungitóxico, encontra-se Ottonia martiana Miq., arbusto da Floresta Atlântica (YUNCKER, 1973), conhecida 
como "anestésia" pelos nativos do litoral paranaense (LOPES, 1989; CUNICO, 2001). Esta espécie pertence à família Piperaceae que se destaca por apresentar em sua composição uma grande diversidade de metabólitos secundários bioativos, dentre eles, as amidas, de grande interesse medicinal (SENGUPTA; RAY, 1987).

Devido à ação anestésica sobre a mucosa bucal, raízes e partes aéreas desta planta são empregadas popularmente no tratamento de odontalgias, in natura, na forma de fragmentos ou alcoolaturas, o que promove alívio imediato da dor (LOPES, 1989; CUNICO, 2001). Apesar desta propriedade medicinal ser popularmente reconhecida, poucos registros com esta espécie vegetal são encontrados na literatura científica, sendo inexistentes publicações de estudos farmacológicos.

Investigações realizadas com outras espécies deste gênero comprovaram o efeito anestésico com sinais de irritação local (KUZE RATES et al., 1997) e permitiram detectar a presença da piperovatina, substância ativa responsável pela ação anestésica e dormência da língua (MAKAPUGAY et al., 1983).

Estudos realizados por LOPES (1989) e CUNICO (2001), com esta espécie vegetal, permitiram o isolamento e identificação das amidas piperlonguminina, isopiperlonguminina e piperovatina, já conhecidas, e comprovaram a existência de potencial antimicrobiano frente a isolados dos fitopatógenos Fusarium oxysporum, Colletotrichum acutatum e Rhizoctonia sp. (CUNICO, 2001).

Pelo exposto, justifica-se a realização de um estudo in vivo da atividade antifúngica de O. martiana frente ao patógeno Cylindrocladium spathulatum, fungo causador da pintapreta, principal doença fúngica em folhas adultas da erva-mate, a qual pode causar até 30 \% de perdas de mudas em viveiro e campo (GRIGOLETTI JÚNIOR \& AUER, 1997).

\section{MATERIAL E MÉTODOS}

\subsection{Material vegetal}

Raízes e partes aéreas de O. martiana foram coletadas em fevereiro de 2002, no Município de Guaratuba (encosta da Floresta Atlântica - Serra do Mar), no Estado do Paraná, a uma altitude de 20 metros.

A identificação da espécie botânica foi realizada pelo Dr. Gerdt Hatschbach do Museu Botânico Municipal (MBM) da Prefeitura de Curitiba, Paraná, e um exemplar desta espécie (exsicata) encontra-se depositado no Herbário deste Museu, devidamente catalogado e registrado sob n 259.057 .

\subsection{Preparação dos extratos vegetais}

O material coletado (raízes e partes aéreas) foi submetido a uma dessecação em estufa com tiragem de ar úmido, à temperatura de $40^{\circ} \mathrm{C}$ durante 48 horas para estabilização ( $\sim 10 \%$ de umidade) e conservado ao abrigo de luz e umidade.

Em seguida, $700 \mathrm{~g}$ da droga vegetal foram maceradas, por três vezes, durante 7 dias com etanol a 95\% (700 g/2 L). Após filtração, o extrato foi concentrado em rota-vapor $\left(40^{\circ} \mathrm{C}\right)$, levado à completa secura, no Laboratório de Fitoquímica, do Departamento de Farmácia, UFPR. 
2.3 Avaliação da atividade antifúngica

A atividade antifúngica foi avaliada in vivo, pelo método de QUIRINO et al. (1999), testando-se o extrato bruto seco solubilizado em água estéril (EBS) frente a um isolado de Cylindrocladium spathulatum. Este isolado foi obtido de lesões foliares em erva-mate, no Laboratório de Fitopatologia da Embrapa Florestas.

Para a montagem do ensaio, 30 folhas maduras foram coletadas de árvores de ervamate. As folhas foram lavadas com água estéril antes da aplicação dos tratamentos. Porteriormente, dez folhas foram tratadas com a solução de EBS de O. martiana (1000 ppm), dez com solução de fungicida benomyl (1000 ppm) e dez sem tratamento (controle). Em seguida, as folhas foram identificadas e acondicionadas em bandejas forradas com papel de filtro úmido e estéril, com a parte abaxial voltada para cima.

Após 24 horas, discos de papel esterelizados $(6 \mathrm{~mm})$ e impregnados com suspensão de esporos de C. spathulatum $\left(1,75 \times 10^{5}\right.$ conídios $\left./ \mathrm{mL}\right)$ foram colocados sobre as folhas previamente preparadas ( 2 discos por folha).

As bandejas com as folhas foram mantidas em laboratório sob condição de temperatura ambiente e iluminação natural por sete dias. Após este período de incubação, fez-se a leitura medindo-se a área dos halos de crescimento da colônia a partir de duas medidas diametrais.

O delineamento experimental do teste de atividade antifúngica foi inteiramente casualizado, e a análise estatística fez-se a comparação das médias pelo Teste de Tukey, com limite de confiança de 95\%, utilizando-se o programa SANEST (ZONTA; MACHADO; SILVEIRA, 1984).

\section{RESULTADOS E DISCUSSÃO}

TABELA 1 - Inibição \% de crescimento de lesões de Cylindrocladium spathulatum quando testado "in vivo" com extrato bruto de Ottonia martiana (Footnotes)

\begin{tabular}{lcc}
\hline & Área média da lesão foliar & Inibição (\%) \\
\hline Controle(água) & 3.2809 & 0.0 \\
EBS de O. martiana (1000 ppm) & 1.8581 & 43.37 \\
Controle (benomyl, 1000 ppm) & 0.0 & 100 \\
\hline
\end{tabular}

* Média de dez folhas

Os resultados deste ensaio demonstraram que a 0 . martiana apresenta potencial antifúngico, pois o seu extrato inibiu em mais de $40 \%$ o crescimento de C. spathulatum em folhas de erva-mate (Tabela 1).

A inibição do crescimento micelial foi determinada pela equação:

I (\%) = [(área média da lesão do controle (água) - área média da lesão dos tratamentos) / (área média do controle (água))] x 100

A partir da Figura 1, pode-se visualizar o efeito do EBS de O. martiana na produção de lesões de C. spathulatum. A ação do EBS (1000 ppm) atuou com aproximadamente metade do poder de benomyl (1000 ppm), indicando que o aumento da concentração para 2000 ppm poderia simular o controle feito pelo fungicida. 


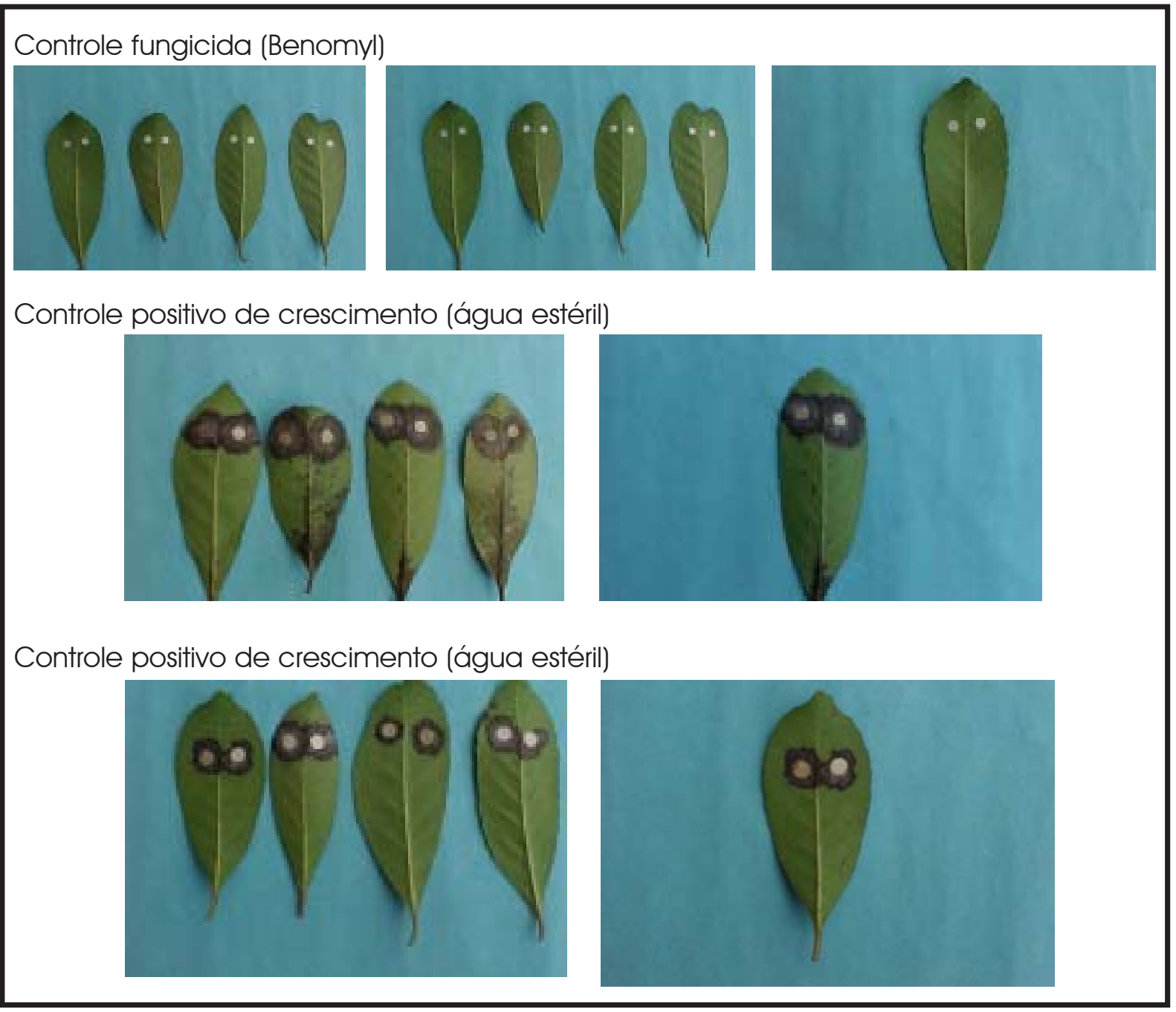

Figura 1 - Visualização do teste in vivo de Ottonia martiana frente à Cylindrocladium spathulatum em folhas de erva-mate.

Estudos relacionados ao controle alternativo de doenças em plantas realizados por STANGARLIN et. al. (1999), demonstraram o grande potencial de plantas medicinais no controle de fitopatógenos, tanto por sua ação fungitóxica direta, inibindo o crescimento micelial e a germinação de esporos, quanto pela indução de fitoalexinas, compostos com característica de elicitores.

Entretanto, novos testes deverão ser realizados, pois a busca por defensivos alternativos que utilizam compostos químicos naturais presentes nas plantas apresenta-se como método alternativo vantajoso, ecologicamente correto

ecolóeco e de

custo reduzido para aquisição e emprego.

\section{Conclusão}

O EBS de O. martiana apresenta potencial antifúngico frente ao isolado Cylindrocladium spathulatum em folhas de erva-mate.

Nesta ótica, a O. martiana poderá oferecer perspectivas para obtenção de substâncias naturais com atividade antimicrobiana, que possibilitaria a aquisição de maiores 
conhecimentos que reforcem a possível utilização de extratos brutos vegetais como método alternativo no controle de doenças fitopatogênicas. Desta forma, a produção dos alimentos, espécies vegetais e fitoterápicos com qualidade serão asseguradas, não somente para as gerações presentes, mas também, para as gerações futuras.

\section{Agradecimentos}

Ao Dr. Gerdt Hatschbach do Museu Botânico Municipal da Prefeitura de Curitiba (MBM), pela identificação da espécie vegetal e ao coletor Osmar S. Ribas do MBM (n 3633), pela obtenção do material vegetal estudado.

\section{REFERÊNCIAS}

COUTINHO, H. L. C. Diversidade microbiana e agricultura sustentável [online]. CNPS/EMBRAPA, 1996.

Disponível em: http://www.bdt.org.br/ marinez/padct.bio/cap9/1/heitor.html. Arquivo capturado em 10 de dezembro de 1999.

CUNICO, M. M. . Estudo fitoquímico e das atividades antimicrobianas da Ottonia martiana Miq. - Piperaceae. 2001 . 83f. Dissertação (Mestrado em Ciências Farmacêuticas) - Setor de Ciências da Saúde, Universidade Federal do Paraná, Curitiba.

GRIGOLETTI JUNIOR, A.; AUER, C.G. Doenças da erva-mate. KIMATI, H.; AMORIM, L.A.; BERGAMIN FILHO, A.; CAMARGO, L.E.A., REZENDE, J.A.M. eds. Manual de Fitopatologia. doenças das plantas cultivadas. 3 ed. São Paulo, 1997, V.2, p.345-347.

KUZE RATES, S. M.; CHAVES, C. G.; VON POSSER, G. L. Investigation of local anesthetic effect and toxicity of Ottonia propinqua (Piperaceae). Acta Farm. Bonaerense, La Plata, v. 16, p. $113-11$ 16, Apr.-Jun., 1997.

LOPES, M. Contribuição para o estudo fitoquímico de Ottonia martiana Miq. - Piperaceae. 1989. 102f. Dissertação (Mestrado em Botânica) - Setor de Ciências Biológicas, Universidade Federal do Paraná, Curitiba.

MAKAPUGAY, $\mathrm{H}$. et al. Piperovatine, the tongue-numbing principle of Ottonia frutencens. J. Ethnopharmacol., Shannon-Ireland, v.7, p.235-238, Mar., 1983.

QUIRINO, V. F.; SZEREMETA, B.; GRIGOLETTI JR, A.; AUER, C. G. Efeito do extrato aquoso de folhas de seis espécies florestais sobre a germinação e crescimento micelial de Cylindrocladium spathulatum e Colletotrichum sp. Revista Summa Phytopathologica, v. 26, n. 1, p. 141, 2000.

SENGUPTA, S.; RAY, A. B. The chemistry of Piper species: a review. Fitoterapia, Milão, v.63, n.3, p. 147-166, 1987. STANGARLIN, J. R. et al. Plantas medicinais e controle alternativo de fitopatógenos. Biotecnol. Ciênc. Desenv., Brasília, v.2, n.11, p.16-21, nov.- dez., 1999.

YUNCKER, T. C. The Piperaceae of Brazil. Hoehnea. São Paulo, v.3, p. 121-3, 136-8, 1973.

ZONTA, E. P.; MACHADO, A. A.; SILVEIRA JÚNIOR, P. Sistema de Análise Estatística para Microcomputadores. SANEST. Pelotas, RS. UFPEL, 1984. 2 disquetes; $3^{1 / 2}$ pol. Programa Estatístico para Microcomputadores. 